\title{
ENTREVISTA COM LEONARDO FRÓES
}

\author{
Anna Olga Prudente de Oliveira ${ }^{1}$ \\ 1Pontifícia Universidade Católica do Rio de Janeiro \\ Rio de Janeiro, Rio de Janeiro, Brasil
}

Publicada em 2015 pela Cosac Naify, a tradução de Leonardo Fróes da obra Contos de Mamãe Gansa de Charles Perrault apresenta ao público leitor brasileiro algumas das histórias mais célebres da literatura infantojuvenil. Poeta comtemplado com o prêmio Jabuti, em 1996, por sua obra Argumentos Invisíveis, e um dos mais reconhecidos tradutores brasileiros, Leonardo Fróes traduziu quase cem obras de prosa e poesia, como, por exemplo, Contos Completos de Virginia Woolf, O triunfo da vida de Percy Shelley e Middlemarch de George Eliot, trabalho pelo qual recebeu o Prêmio Paulo Rónai de tradução, em 1998.

Nesta entrevista com o tradutor, busca-se conhecer seu trabalho, seu entendimento sobre a obra de Perrault e suas propostas e estratégias tradutórias, especialmente em relação aos contos elaborados pelo escritor francês do século XVII. A obra Histoires ou Contes du temps passé avec des Moralités ou Contes da ma Mère l'Oye (Histórias ou Contos do tempo antigo com Moralidades ou Contos de Mamãe Gansa) foi publicada em 1697 na França, contendo uma dedicatória à sobrinha do rei Luís XIV, intitulada À Mademoiselle ${ }^{l}$, e oito contos em prosa com moralidades em verso ao final de cada história: La Belle au bois dormant, Le Petit Chaperon rouge, La

\footnotetext{
${ }^{1}$ Embora a autoria da obra hoje seja atribuída a Charles Perrault, essa dedicatória com assinatura de P. Darmancour, filho do autor, suscitou controvérsia sobre a autoria dos contos.
} 
Barbe Bleue, Le Maitre Chat ou Le Chat botté, Les Fées, Cendrillon ou La Petite Pantoufle de verre, Riquet à la houppe e Le Petit Poucet; em português, conforme a tradução de Leonardo Fróes, A Bela Adormecida, Chapeuzinho Vermelho, O Barba Azul, O Gato Mestre ou O Gato de Botas, As Fadas, Cinderela ou A Gata Borralheira, Riquet, o Topetudo e $O$ Pequeno Polegar (Perrault, 2015). Uma característica que distingue a referida obra em relação a outros contos de fadas é a moralidade em verso ao final da história contada em prosa. Apresentando uma tradução integral dos contos de Perrault, Leonardo Fróes mantém as moralidades em verso, tendência vista em novas reescritas brasileiras da obra de Perrault.

$\mathrm{Na}$ entrevista, a seguir, Leonardo Fróes aborda sua formação, seu trabalho como tradutor, sua compreensão acerca da obra de Perrault e seu projeto de tradução.

Cadernos de Tradução (CT): Leonardo, para iniciarmos nossa conversa sobre os contos de Perrault e a sua tradução Contos da Mamãe Gansa, publicada pela Cosac Naify em 2015, gostaria que comentasse um pouco sobre sua formação e experiência como tradutor. Como o poeta Leonardo Fróes se torna tradutor? Poderia falar sobre sua experiência no exterior - já trabalhava com tradução ou começou a traduzir ao retornar ao Brasil? Tem alguma preferência em relação aos idiomas com os quais trabalha?

Leonardo Fróes (LF): Comecei trabalhando em jornal e, aos 19 anos, revendo traduções do francês, na Editora Delta-Larousse, no Rio. Pouco depois trabalhei na Appleton Century Crofts, em Nova York, como membro de uma equipe que criou dois dicionários, um inglês-português e outro português-inglês, para venda nos Estados Unidos. Sempre fiz pequenas traduções, durante o tempo em que vivi no exterior, mas só depois de voltar para o Brasil, com 26 anos, tornei-me de fato um tradutor profissional. Quatro anos depois, desde que passei a morar em Petrópolis, sem um emprego 
fixo, a tradução foi meu principal meio de vida. Os seis anos em que morei e trabalhei no exterior foram fundamentais para minha formação, mas também, bem antes disso, os estudos no Colégio Pedro II, no qual entrei em 1952 e cujo currículo incluía, no meu tempo, nos cursos ginasial e clássico, seis línguas estrangeiras: latim, grego, francês, inglês, espanhol e alemão. Não tenho preferência em relação a idiomas, mas só traduzi daqueles nos quais me sinto mais à vontade, quase sempre inglês e francês e, em muito menor escala, espanhol e alemão.

CT: Em entrevista a Julia de Carvalho Hansen (Caderno de Leituras $n .64$, p.5), você diz "o tradutor, o ensaísta e o poeta nos quais a vida me moldou são para mim apenas diferentes facetas de uma mesma pessoa”, apontando, a meu ver, para a dimensão não apenas intelectual mas também artística da tradução. E, em sua fala em Tertúlia - Encontros da Literatura, chamou-me atenção também a imagem que você propõe do tradutor que, ao realizar seu trabalho, se despersonaliza e incorpora uma linguagem e um universo que até então não eram seus (Tertúlia - Encontros da Literatura, SESC Pompeia, 13/09/2009, v.7-8/13). Em que medida uma atividade interfere na outra ou a complementa? O traduzir expande o universo do poeta? A tradução pode ser vista como uma forma de criação literária na qual o escritor-tradutor pode experimentar estilos ou literaturas diferentes dos seus enquanto escritor-poeta?

$L F$ : Traduzir sempre foi para mim, antes de tudo, uma maneira de garantir meu sustento. Nunca formulei um objetivo de me afirmar intelectualmente como tradutor. Mas, como sempre traduzi bons autores, é claro que a atividade acabou se tornando por demais prazerosa e criativa. Acho sim, como você lembra, que é bom o tradutor se distanciar de sua própria pessoa, de seus gostos, convicções e eventuais pré-conceitos, para se deixar conduzir pelo outro, aquele autor que ele tem a incumbência de recriar. Ou: aquela autora. Já traduzi ficção e poesia escritas por mulheres, 
como George Eliot, Virginia Woolf, Flannery O'Connor e Elizabeth Barrett Browning, e o processo de despersonalização, nesses casos, teve de ser ainda maior. A tradução literária por certo me ajudou a entender outros sistemas, estilos, visões, modos de ser, e por isso sempre teve e continua a ter grande importância para minha própria atividade como escritor.

CT: No documentário Leonardo Fróes: um animal na montanha de Alberto Pucheu, Gabriela Capper e Sérgio Cohn, além do privilégio de ouvir alguns de seus poemas pela voz do próprio poeta, podemos conhecer o seu pensar sobre a poesia. Você menciona uma diferenciação entre a poesia escrita e a poesia do momento, esta última, uma forma de vida poética. Em relação à poesia escrita, como você a entende? E quais seriam as estratégias necessárias à tradução de poesia?

LF: Creio que só há um modo de bem traduzir poesia escrita, sobretudo se ela for mais antiga, com métrica e rima, que é recriar. As estratégias são ditadas pelas circunstâncias concretas de cada texto, não há como fixar critérios únicos que sempre tenham a mesma validade. Recriando poemas, nunca me permiti no entanto uma liberdade absoluta em relação aos originais. Sou pautado por eles, e sempre tento deixar a minha voz em surdina.

CT: A edição da Cosac Naify de Contos da Mamãe Gansa tem um projeto gráfico muito especial e ilustrações do estúdio de design Milimbo. Os ilustradores Trinitat Olcina Bas e Juanjo Oller utilizam técnicas de ilustração diferentes para cada um dos contos, tais como desenhos à mão, colagens e cenários fotografados, criando uma linguagem própria a cada conto. Gostaria que comentasse algumas questões sobre esse projeto editorial. Como surgiu o projeto de traduzir os contos de Perrault - foi um convite da Cosac? Qual foi a edição utilizada como texto fonte? Porque foi utilizado como texto 
fonte a versão em prosa do conto Pele de Asno, surgida já no século $X I X$, e não o conto publicado integralmente em verso ao final do século XVII? Houve algum tipo de orientação por parte da editora em relação a normas, critérios linguísticos ou literários a serem seguidos? Quanto tempo levou o seu trabalho de tradução da obra havia um prazo? Você teve alguma participação nessa composição do texto com as ilustrações - o que achou do resultado? E em relação ao processo de revisão, você teve algum retorno ou participação antes da edição ficar pronta? Saberia dizer qual foi a tiragem da edição? Recebe direitos autorais pela sua tradução? Com o fim da Cosac, há alguma previsão de reeditar a obra em outra editora?

$L F$ : A tradução de Contos da mamãe gansa foi uma simples encomenda da Cosac. Como em geral nesses casos, não tive nenhuma participação no projeto editorial ou na parte gráfica. Só o texto me foi pedido, e em relação a ele não houve nenhuma recomendação. Só vi as ilustrações depois de prontas, mas gostei muito delas. A revisão foi feita sob meu controle. Não havia prazo para terminar o trabalho, mas não me lembro mais (fiz esta tradução, se não me engano, em 2013) quanto tempo levei. Não sei qual foi a tiragem. Sempre recebo direitos autorais pelos meus trabalhos. Com o fim da Cosac, não há ainda previsão de reedição por outra editora.

A tradução seguiu na íntegra o texto de 1697 (que traz o nome do pai na capa e o de seu filho na dedicatória à princesa), com as moralidades em versos e as cenas horripilantes que em geral são cortadas nas adaptações desses contos em países e línguas de todo o mundo. Três livros foram usados como fontes, valiosos não só por darem esse texto, na ortografia de três diferentes épocas, mas também pelas notas e comentários que trazem e se mostraram fundamentais para o trabalho: Oeuvres Choisies de Charles Perrault, org. Jacques-Albin-Simon Collin De Plancy (Paris: Brissot-Thivars et Cie., Libraires, 1826); Les Contes de Perrault et les récits parallèles (leurs origines), de Pierre Saintyves (Paris: Robert Laffont, 1987); e, de Charles Perrault, a excelente edição bilíngue L'integrale des Contes en vers et en prose/ The Complete Fairy Tales in 
Verse and Prose, org. e trad. Stanley Appelbaum (Mineola, New York: Dover, 2002). A versão em prosa do conto "Pele de Asno", versão essa cuja verdadeira autoria nunca se esclareceu muito bem, provém da primeira edição (1781) que trouxe todos os contos, quer em prosa, quer em versos, atribuídos a Charles Perrault. Apesar das dúvidas quanto à sua autoria, desde então se tornou praxe incluir o "Pele de Asno" em prosa entre os Contos da mamãe gansa. A simplicidade da linguagem utilizada nos nove contos em prosa, pelos quais Perrault se imortalizou, destoa do estilo mais rebuscado dos seus três contos em versos - Grisélidis ("Griselda"), Peau d'Âne ("Pele de Asno") e Les Souhaits Ridicules ("Os Desejos Ridículos") - publicados por ele anteriormente, em 1695.

CT: No Apêndice da edição da Cosac Naify temos seu texto "A delicadeza das duas línguas", no qual você menciona os três autores franceses do século XVII que traduziu, Jean de La Fontaine, François-Timoléon de Choisy e Charles Perrault. Ao final você apresenta sua tradução de um trecho de Timoléon de Choisy, comentando identificar-se com este pensamento:

Quando leio um livro simplesmente a fim de entende-lo, ligo-me apenas nas palavras; mas é preciso que eu me ligue nas frases, se quiser traduzi-lo. Cada língua tem os seus modos de dizer. E, se eu traduzir palavra por palavra, disso resultará uma linguagem ridícula. É preciso que eu encontre um jeito francês que corresponda ao jeito português; caso de fato o encontre, é encontrando-o que percebo, tanto quanto ao meu alcance, a delicadeza das duas línguas. (PERRAULT, 2015, Apêndice, p. 11)

A concepção de tradução delineada nessa passagem faz com que possamos entender o tradutor como um profundo conhecedor de 
sua língua e cultura, alguém que trabalha com a sutileza, com as nuances da língua. Sua tradução dos contos de Perrault recria um universo, sem entretanto fazer concessões em termos de simplificação da linguagem ou de apagamento de fatores culturais, por exemplo. Como é esse trabalho com a linguagem? O texto de Perrault, com suas ironias e seus subtextos, é facilmente compreensível para um leitor da obra em francês? E em sua reescrita, como foi o trabalho para projetar esse francês do século XVII em nosso portuguêsbrasileiro do século XXI?

$L F$ : O texto de Perrault é simples, mas como qualquer outro tão antigo coloca certas dificuldades, que pude superar recorrendo às notas e comentários das edições às quais me reportei. Não me considero "um profundo conhecedor" de nada, mas escrevo e faço traduções há bem mais de meio século. É compreensível, assim, que eu tenha uma boa prática, e sempre foi praticando que aprendi o pouco que sei. A qualquer tradutor, recomendo antes de tudo bom senso. Se isso estiver em uso, saberemos como lidar com ironias, duplos sentidos, imagens polivalentes. O trecho do abade de Choisy, em sua simplicidade, é para mim uma lição preciosa. Compreender a delicadeza das duas línguas já facilita, e muito, todo o restante.

CT: Há uma característica literária marcante nos oito contos da obra publicada em 1697 Histoires ou contes du temps passé avec des moralités (La Belle au bois dormant, Le Petit Chaperon rouge, Barbe Bleue, Le Maître Chat ou Le Chat Botté, Les Fées, Cendrillon ou La petite pantoufle de verre, Riquet à la houppe, Le Petit Poucet), que é justamente o conto em prosa seguido da chamada moralidade em verso. Em muitas reescritas brasileiras dos contos essa característica é apagada com a exclusão das moralidades em verso. Isso ocorre tanto em reescritas antigas, como a de Figueiredo Pimentel (Quaresma, 1896/Villa Rica, 2006) e a de Monteiro Lobato (Companhia Editora Nacional, [1936]/2007), 
como por exemplo em uma adaptação recente publicada por Walcyr Carrasco (Moderna, 2013). Entendo que há uma relação simbiótica da moralidade com o conto, as moralidades não seriam assim poemas independentes, apesar de suas características formais, mas se completariam com os contos. E, ainda, seriam uma espécie de voz autoral sobre a história narrada. Como você vê as moralidades em verso dos contos em prosa - são poemas? Como foi o trabalho de recriação de ritmo, métrica e rimas - o que priorizou ao traduzir as moralidades?

$L F$ : Respondi essa pergunta, em parte, no item 4. Não conheço as outras traduções que você menciona, nunca sequer as vi, nem nenhuma outra em português. A tradução para o inglês de Stanley Appelbaum, que mencionei antes, me foi útil sobretudo pelas notas e comentários, por ser este tradutor um especialista na literatura francesa da época de Perrault. Minha norma, como tradutor, é respeitar as decisões autorais. Por isso traduzi as moralidades, que são parte do texto original. Não me coube julgá-las, mas sim apenas refazê-las com o máximo de fidelidade possível. Por outro lado, entendo que é inútil protestar contra adaptações, recriações ou contrafações de obras antigas, porque elas hoje, em todo o mundo, são fatos consumados. Muitas podem até ter seu valor, embora não seja essa a linha preferencial que segui.

CT: Em minha pesquisa sobre as reescritas de Perrault no Brasil considero que as traduções e as adaptações produzem determinadas imagens do autor no sistema literário meta; os reescritores geramnovas leituras e interpretações da obra o que possibilita sua permanência ao longo do tempo. Os contos de Perrault têm sido reescritos no Brasil desde os primórdios da literatura infantojuvenil brasileira, ao final do século XIX, publicados por exemplo em Contos da Carochinha (Quaresma, 1896) de Figueiredo Pimentel, que adaptou à época diversos contos populares da tradição europeia. E até hoje novas reescritas são feitas, tais como a sua e a de outros tradutores, 
como Ivone Benedetti, Maria Luiza Borges e Mário Laranjeira, só para citar alguns, que publicaram suas traduções, respectivamente, pela L\&PM (2012), Zahar (2010) e Iluminuras (2007). Assim como a sua tradução, essas últimas três traduções mencionadas têm como característica comum a manutenção do texto integral. Conhece essas ou outras reescritas brasileiras da obra de Perrault? Alguma delas influenciou o seu trabalho? Qual a relevância de novas reescritas $e$ leituras (tanto em novas edições francesas como em novas edições em outras línguas) de uma obra como a de Perrault (um cânone literário nem sempre lido em textos integrais)? Que imagem desse autor podemos ter com a leitura da sua tradução?

$L F$ : Acabo de responder no item anterior. Não conheço, nunca vi nenhuma dessas traduções. Aliás, nos pouquíssimos casos em que traduzi textos já traduzidos por outros, sempre fiz questão de não ler nem consultar eventuais trabalhos precedentes.

CT: Na ficha catalográfica da edição da Cosac Naify a obra é classificada como literatura infantojuvenil (LIJ). E, embora os contos tenham sido escritos em uma época em que não havia uma literatura infantojuvenil propriamente dita, Perrault tornou-se no mundo ocidental um cânone da LIJ. O que acha dos contos de Perrault enquanto literatura e dessa escrita do autor que surge como reescrita de contos já existentes e popularmente conhecidos da tradição oral? Há um público alvo especialmente visado em sua tradução? Há alguma diferença entre a tradução de literatura $e$ da literatura classificada como infantojuvenil, em termos de estratégias de tradução?

$L F$ : Em quase uma centena de livros que traduzi, apenas quatro são para crianças ou jovens. Só nos últimos anos fiz trabalhos nessa área, porque as propostas eram financeiramente compensadoras. Lido com textos, e é no momento em que os enfrento que decido como irei proceder. $\mathrm{O}$ único alvo da minha tradução foi ser fiel ao 
original. Alvos comerciais dizem respeito às editoras. Alvos conceituais ou analíticos dizem respeito a especialistas na área, o que não é o meu caso.

CT: Para traduzir Perrault imagino que o tenha estudado mais profundamente como faz com os autores que lhe aparecem para traduzir. O que leu sobre Perrault? Como esse processo de pesquisa auxilia o seu trabalho de tradução? Tem algum conto preferido?

LF: Li as Oeuvres Choisies de Perrault, na edição de 1826 que mencionei no item 4, da qual consegui na França uma reimpressão fac-similar, e isso apenas para chegar à conclusão de que ele não é um autor muito notável, ficando bem abaixo, em termos qualitativos, de contemporâneos seus como La Fontaine ou o abade de Choisy. As Mémoires de Perrault, por exemplo, são um relato enfadonho do envolvimento que ele teve na construção de obras reais, das quais foi, por muito tempo, superintendente. De si mesmo, quase ele não fala. Seu poema mais famoso, o longo "Le Siècle de Louis-le-Grand", é uma bajulação sem graça do rei ao qual ele serviu, Luís XIV. Facilmente se conclui que sua grande realização literária foi o livro ao qual seu nome permanece ligado, os Contos da mamãe gansa. Li também sobre ele, com grande proveito, o livro de Pierre Saintyves, igualmente mencionado no item 4, e o muitíssimo bem documentado Le Dossier Perrault, de Marc Soriano (Paris: Hachette, 1972). Ler outras obras do autor que estou traduzindo, ou livros sobre ele, é uma norma que sempre sigo em meu trabalho. Respondendo à última pergunta, digo que não, não tenho um conto preferido, todos me parecem interessantes.

CT: Em um dos momentos marcantes de sua fala em Tertúlia Encontros da Literatura, mencionando práticas editoriais que por vezes violentam o texto do autor, você fala da necessidade de nos abrirmos para a compreensão e aceitação dos outros hábitos, do 
respeito pelo outro e da harmonia que pode ser gerada quando se vai ao encontro do outro (Tertúlia, v.5/13). Considera que a tradução tem o papel de aproximar universos que de outro modo não poderiam se conhecer e dialogar? É um trabalho político nesse sentido? E, por favor, fale sobre o amor, quando diz que "é preciso que o tradutor se tome de amor por aquele autor que está traduzindo" (Tertúlia, v.4/13). O papel do tradutor seria conseguir com sua tradução se colocar no lugar do que é outro, $e$ assim ampliar seu próprio universo, mas também o do outro como a imagem que você sugere do instrumentista que amplia as possibilidades de interpretação de uma partitura musical?

$L F$ : Remeto aos itens 2 e 3 , nos quais já abordei as mesmas questões. Mas ainda posso dizer que a tradução, para mim, é um aprendizado eterno. Não só em relação a este exercício, tão gratificante, que é tentar entrar, com admiração e respeito, na cabeça de um outro. Como traduzi sobretudo autores mais antigos, em especial do século XVII à primeira metade do XX, frequentemente tive de estudar muito para me preparar para o trabalho. É preciso mergulhar nas épocas de que as obras datam, não só no que se refere à linguagem, como também, não raro, nas circunstâncias sociais e políticas que então prevaleciam. Para traduzir os Panfletos satíricos de Swift, para dar um exemplo bem expressivo, tive de ler uns trinta livros. Sim, é verdade, várias vezes tenho usado essa comparação entre o tradutor e um instrumentista para falar do meu trabalho. Ambos têm de seguir uma pauta, uma partitura, mas ao mesmo tempo não podem se desvincular totalmente de quem são, de seus modos de ser, das circunstâncias que os condicionam a uma existência histórica. Não é só por dinheiro que trabalho. É também, e sobretudo, pelo imenso prazer que extraio do meu trabalho. Traduzo por encantamento. Swift, Shelley, Goethe, Virginia Woolf, Faulkner, Elizabeth Barrett Browning, todos esses e muitos outros autores que traduzi foram se tornando para mim pessoas muito queridas. Há uma espécie de amor literário, que existe por si mesmo e prescinde de qualquer ideia de posse. 


\section{Referências}

CARRASCO, Walcyr. Contos de Perrault recontados por Walcyr Carrasco. São Paulo: Moderna, 2013.

FRÓES, Leonardo. Tertúlia - Encontros da Literatura, SESC Pompeia, 13/09/2009. Publicado em 14 de dez de 2009. Leonardo Fróes, tradutor do livro Contos Completos, de Virginia Woolf - convidado da série 'tradutores' do projeto Tertúlia - Encontros da Literatura. Transmissão ao vivo 13/9/2009, do SESC Pompeia.

HANSEN, Júlia de Carvalho. Entrevista com Leonardo Fróes por Júlia de Carvalho Hansen. Caderno de Leituras, 64. [S.L], Edições Chão da feira, 2017.

LOBATO, Monteiro. A Barca de Gleyre. 2vol. São Paulo: Brasiliense, 1951.

PERRAUlT, Charles. Contes. Édition critique Jean-Pierre Collinet. Folio classique. Paris, Gallimard, 2013.

- Contos da mamãe gansa ou histórias do tempo antigo. Tradução: Leonardo Fróes. Posfácio: Michel Tournier. São Paulo: Cosac Naify, 2015.

. Contos de Mamãe Gansa. Tradução e introdução: Ivone C. Benedetti. Porto Alegre, RS: L\&PM, 2012.

. Contos de fadas de Perrault, Grimm, Andersen \& outros. Apresentação: Ana Maria Machado. Tradução: Maria Luiza X. de A. Borges. Rio de Janeiro: Zahar, 2010.

. Contos de fadas. Tradução: Monteiro Lobato. 2 ed. São Paulo: Companhia Editora Nacional, 2007.

- Contos e fábulas: Charles Perrault. Tradução e posfácio: Mário

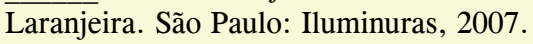


PIMENTEL, Figueiredo. Contos da Carochinha. Rio de Janeiro: Quaresma \& CA Livreiros Editores, 1911.

PUCHEU, Alberto; CAPPER, Gabriela; COHN, Sérgio. Leonardo Fróes: um animal na montanha. Documentário de Alberto Pucheu, Gabriela Capper e Sérgio Cohn. Publicado em 29 de maio de 2017.

ROCHA, Ruth. Contos de Perrault. Ilustrações Cárcamo. São Paulo: Moderna, 2010.

Recebido em: 14/04/2018

Aceito em: 13/07/2018

Publicado em setembro de 2018

Anna Olga Prudente de Oliveira. E-mail: AnnaOlga@terra.com.br

ORCID: https://orcid.org/0000-0001-6480-0654

Cad. Trad., Florianópolis, v. 38, no 3, p. 487-499, set-dez, 2018 